\title{
FENOMENOLOGIA: UMA ALTERNATIVA PARA PESQUISA EM ENFERMAGEM *
}

\author{
Adriana Katia Corrêa **
}

CORREA, A.K. Fenomenologia: uma alternativa para pesquisa em enfermagem. Rev.latino-am.enfermagem, Ribeirão Preto, v. 5, n. 1, p. 83-88, janeiro 1997.

Um dos caminhos metodológicos que pode ser utilizado nas pesquisas é a fenomenologia, que se originou como um movimento na filosofia, sendo aplicada, posteriormente, às ciências humanas. Na enfermagem a utilização da fenomenologia também representou uma busca de alternativa metodológica de pesquisa. A proposta deste trabalho é contribuir com alguns subsídios teóricos para a compreensão do referencial fenomenológico. Inicialmente, apresenta algumas idéias básicas da fenomenologia, enquanto corrente filosófica para, posteriormente, tratá-la enquanto alternativa metodológica de pesquisa, até abordar sua utilização, pelos enfermeiros, enquanto metodologia de investigação.

UNITERMOS. enfermagem, fenomenologia, pesquisa

O homem, no desenvolvimento de sua própria história procura o sentido da vida, de si mesmo e do mundo. Nessa busca de conhecimentos, inúmeros caminhos mostram-se como possibilidades de apreensão da realidade, baseados em posturas filosóficas diversas.

Um dos caminhos metodológicos para a pesquisa é a fenomenologia, que se originou como um movimento na filosofia, sendo aplicada, posteriormente, às ciências humanas.

$\mathrm{Na}$ enfermagem, a utilização da fenomenologia também se deu enquanto busca de alternativa metodológica de pesquisa que contemplasse a natureza de certos objetos de investigação.

Acredito que o assumir esse referencial implica não somente compreendê-lo enquanto uma maneira de pesquisar, mas fundamentalmente, compreendê-lo enquanto um pensar que fundamenta um "ver" o mundo, pensar esse que necessariamente tem que fazer sentido para o pesquisador, não se tratando apenas de um entendimento intelectual.

Neste trabalho, minha proposta é contribuir com alguns subsídios teóricos para a compreensão do referencial fenomenológico.

\section{IDÉIAS BÁSICAS DA FENOMENOLOGIA}

\author{
Conforme comentado por CAPALBO (1984), J.H.
}

Lambert usou, pela primeira vez, em 1764, a palavra fenomenologia que, inicialmente, foi compreendida como teoria da aparência, visão falsa da realidade. Em 1804, Fichte usou a fenomenologia num sentido diferente de Lambert, porém, mantendo a idéia de teoria da aparência, que para ele era a manifestação de algo real, verdadeiro, uma revelação. Com Hegel, que se dedicou ao estudo do movimento do espírito, a fenomenologia definiu-se enquanto método e filosofia. No entanto, foi no início do nosso século que a fenomenologia se afirmou como uma linha de pensamento, com Edmund Husserl.

Assim, o verdadeiro fundador do movimento fenomenológico foi Husserl (1859-1938) na Alemanha, que utilizou o nome antigo de fenomenologia, imprimindo-lhe um novo significado: método de apreender e dizer os fenômenos, que se referem à realidade que se manifesta por si mesma (FRANCA, 1978).

É importante compreender, mesmo que de forma breve, o panorama científico no qual se desenvolveu a fenomenologia, com Husserl, no final do século XIX e início do século atual.

Nos dez últimos anos do século XIX, quando se iniciaram os primeiros trabalhos de Husserl, a ciência, alicerçada no modelo positivista, preenchia o espaço vazio deixado pela filosofia especulativa, destacandose, sobremaneira, a matemática e a psicologia. Porém, a partir de 1880, a segurança do pensamento positivista começa a ser abalada, tornando-se os fundamentos e o

\footnotetext{
*Este trabalho é adaptado da dissertação de mestrado: "Sendo Enfermeira no Centro de Terapia Intensiva", orientada pela Profa Dra Elizabeth Ranier Martins do Valle, apresentada à Área de Enfermagem Fundamental do Programa de Pós Graduação da Escola de Enfermagem de Ribeirão Preto da Universidade de São Paulo, em abril de 1995

** Enfermeira, Mestre em Enfermagem Fundamental
} 
alcance da ciência, objeto de interrogação. Nessa época, Husserl, cuja formação básica era a matemática, passou a dedicar-se às questões filosóficas, entrando em contato com Franz Brentano. Esse filósofo propunha um novo método de conhecimento do psiquismo, explorando o campo da consciência e sua relação com o objeto, e já distinguia os fenômenos psíquicos, que comportam uma intencionalidade, dos fenômenos físicos. O contato com Brentano despertou Husserl para as insuficiências das ciências humanas como desenvolvidas em torno dos anos 1900. O que rejeitava Husserl era o naturalismo dessas ciências que não considerando a especificidade de seu objeto, acabavam por tratá-lo como um objeto físico, sendo confundida a descoberta das causas exteriores de um fenômeno com a natureza própria deste fenômeno. Entre o discurso especulativo da metafísica e o raciocínio das ciências positivas, Husserl buscou outra via que, anterior a qualquer raciocínio, nos colocasse no mesmo plano da realidade, das "coisas mesmas". Assim, propôs Husserl a fenomenologia, como uma volta ao mundo da experiência, do vivido (DARTIGUES, 1973).

A esse respeito comenta HUSSERL (1965, p. 72): “(...) não é das Filosofias que deve partir o impulso da investigação, mas, sim, das coisas e dos problemas $(. . .)^{u}$

Para Husserl, a fenomenologia seria então, "(...) uma ciência rigorosa, mas não exata, uma ciência eidética que procede por descrição e não por dedução. Ela se ocupa de fenômenos, mas com uma atitude diferente das ciências exatas e empíricas. Os seus fenômenos são os vividos da consciência, os atos e os correlatos dessa consciência" (CAPALBO, s.d, p. 14).

Em síntese, tomando como base ainda os dizeres de CAPALBO (1984), a filosofia de Husserl nasceu como reação ao idealismo, divergindo de suas construções a priori, e ao positivismo, já que esse considerava válido apenas o fenômeno empiricamente pesquisado. O lema de Husserl "volta às coisas nelas mesmas" é uma tentativa de aproximação às coisas sem preconceitos ou pressupostos interpretativos. Assim Husserl define a fenomenologia como "ciência dos fenômenos", sendo fenômeno compreendido como o que é imediatamente dado em si mesmo à consciência.

Sendo o fenômeno o objeto de investigação fenomenológica, para aclarar seu significado retorno à sua etimologia: "(...) Do grego phainomenon significa discurso esclarecedor a respeito daquilo que se mostra para o sujeito interrogador. Do verbo phanesthai como mostrar-se, desvelar-se. Fenômeno é, então, tudo o que se mostra, se manifesta, se desvela ao sujeito que o interroga" (MARTINS et al. 1990, p. 141).

Um dos princípios básicos da fenomenologia diz respeito à intencionalidade da consciência. Assim, a consciência é sempre "consciência de alguma coisa", estando dirigida para um objeto. Por sua vez, o objeto também é sempre "objeto-para-um-sujeito". Consciência e objeto não são entidades separadas na natureza, mas, definem-se, respectivamente, a partir dessa correlação. "(...) Se a consciência é sempre consciência de alguma coisa e se o objeto é sempre objeto para a consciência, é inconcebível que possamos sair dessa correlação, já que, fora dela, não haveria nem consciência nem objeto" (DARTIGUES, 1973, p. 26).

Através da noção de intencionalidade, é tentada a superação das tendências racionalistas e empiristas, pretendendo a fenomenologia superar a dicotomia razão-experiência no processo de conhecimento. Ao contrário dos racionalistas, a fenomenologia afirma que não há pura consciência, separada do mundo, mas toda consciência é consciência de alguma coisa. Ao mesmo tempo, contrariando os empiristas, os fenomenólogos afirmam que não há objeto em si, mas o objeto existe para um sujeito, sujeito esse que atribui significados ao objeto (ARANHA \& MARTINS, 1993).

Assim, a partir da fenomenologia, a filosofia acaba por se situar numa dimensão distinta em relação ao conhecimento natural. Tal dimensão corresponde ao método radicalmente novo, o qual se opõe ao método natural (GILES, 1975).

Enfocando a "atitude natural", MOURA (1989) comenta que a mesma se caracteriza por conceber o objeto como em si, independente da percepção, ou seja, é suposta uma separação real entre o objeto e suas manifestações. Ainda, a consciência é apreendida como uma região no interior da totalidade do mundo, limitada por outras regiões, o que supõe um exterior a si. Dessa forma, a atitude natural compreende a dupla decodificação do objeto como em si e da consciência como região. $\mathrm{Na}$ fenomenologia tem-se a mudança dessa atitude, ao ser trabalhada a idéia da redução fenomenológica.

A esse respeito, salienta FORGHIERL (1991) que a redução é uma mudança da atitude natural para a fenomenológica, que nos permite visualizar o mundo e o sujeito como fenômeno, como constituintes de uma totalidade, na qual ambos revelam-se, reciprocamente, como significações.

A relação consciência-objeto mostra-se como o campo de análise da fenomenologia. MARTINS (1992) refere-se à relação noesis-noema, na qual noesis significa o ato intencional da consciência, ou seja, a disposição do sujeito para ver um objeto e noema significa aquilo que é visto. Para o mesmo autor, a análise fenomenológica mais importante pertence ao lado "noético", tratando-se da consciência de um sujeito, que atribui significado a algo que focaliza. A partir desse movimento ocorre uma modificação que pode gerar uma nova atribuição de significado (experiência significativa).

Ao dirigir-se para um fenômeno interrogado, a consciência, na sua intencionalidade, busca a essência 
desse fenômeno, chegando à apreensão de seu significado, ao seu desvelamento. Para que essa essência seja alcançada é preciso reduzir, purificar o fenômeno de tudo que não seja essencial, utilizando-se uma técnica "variação eidética" - que dá ao pensamento a certeza de que será retido apenas o essencial do fenômeno. Assim, imaginam-se todas as variações que o fenômeno poderia sofrer, chegando-se àquilo que não poderia ser suprimido sem a destruição do próprio fenômeno - o que, provavelmente, pertence à sua essência (DARTIGUES, 1973).

Para CAPALBO (1984, p. 139) "é pela descrição e pela variação imaginária dos aspectos acidentais que se chega à essência ou ao invariante, ou ao ser enquanto esse se manifesta tal como ele é em sua essência.

A intuição é doadora de significação, isto é, ela é um ver intelectual que constitui seus objetos. Ela não é um mero olhar, mas sim um ver discernido, um ver inteligente, cuja característica básica é a de significar ou dar sentido a algo (...).

Ainda envolvendo a busca da essência do fenômeno tem-se a "epoché" que significa colocar "entre parênteses" as crenças, pressupostos ou teorias acerca do fenômeno que está sendo interrogado. Assim, o fenômeno é colocado "em suspensão", sendo buscado aquilo que se mostra (MARTINS, 1992).

Tendo em vista a "epoché", retomo a HUSSERL (1965, p. 73): “(...) não é preciso postular-se que se veja com os próprios olhos, mas antes que se deixe de eliminar o visto numa interpretação que os preconceitos impõem (...)".

Em síntese, a fenomenologia tem como enfoque central à compreensão dos fenômenos, dirigindo-se para a vivência cotidiana. Trata-se de buscar o homem em outra perspectiva - a partir do seu sendo-no-mundo. E uma volta ao mundo da vida.

As idéias até aqui mencionadas representam alguns aspectos fundamentais da fenomenología enquanto corrente filosófica. Conforme comenta COHEN (1987), Husserl foi e ainda é a figura central do movimento fenomenológico, porém, a fenomenologia inclui mais que a sua filosofia e, a própria filosofia de Husserl foi diversificando-se no decorrer do tempo. A partir do seu pensamento, outros filósofos desenvolveram suas concepções no enfoque fenomenológico, como Heidegger (1889 - 1976) na Alemanha, Sartre (1905 - 1980) e Merleau-Ponty (1908 - 1961), na França.

\section{A FENOMENOLOGIA COMO MODALIDADE DE PESQUISA}

As considerações aqui apresentadas foram elaboradas tendo como referências básicas: MARTINS \&
BICUDO (1989); MARTINS et al. (1990); MARTINS (1992), BICUDO (1992) e BOEMER (1994).

Enquanto modalidade de pesquisa qualitativa, a fenomenologia busca a compreensão do fenômeno interrogado, não se preocupando com explicações e generalizações. $O$ pesquisador não parte de um problema específico, mas conduz sua pesquisa a partir de uma interrogação acerca de um fenômeno, o qual precisa ser situado, ou seja, estar sendo vivenciado pelo sujeito.

$\mathrm{Na}$ busca de desvelar o fenômeno interrogado, o pesquisador não parte de teorias ou explicações a priori, mas do mundo-vida dos sujeitos que vivenciam o fenômeno em questão. Em outros termos, realizando a "epoché", o pesquisador procura estabelecer um contato direto com o fenômeno situado.

Nessa perspectiva, o pesquisador não parte de um referencial teórico estabelecido a priori, sendo considerado o seu mundo-vida. É através de suas experiências que é possível ao pesquisador interrogar o mundo ao redor.

O que se busca na pesquisa fenomenológica são os significados que os sujeitos atribuem à sua experiência vivida, significados esses que se revelam a partir das descrições desses sujeitos. A descrição "(...) tem o significado de des ex-crivere, isto é, de algo que é escrito para fora" (MARTINS \& BICUDO, 1989, p.45). A descrição de alguma coisa implica em diferenciála de outra, mencionando seus atributos. Considerando que nem sempre é possível obter descrições dos sujeitos acerca do fenômeno em estudo, pode-se recorrer à entrevista.

O momento da entrevista não pode ser visualizado como um procedimento mecânico, mas como um encontro social, uma relação pesquisadorpesquisado caracterizada pela empatia, intuição e imaginação.

Essa forma de se conduzir a pesquisa traz em si a questão da subjetividade. Contudo, tanto o sujeito como o fenômeno estão no mundo-vida com outros sujeitos, que também percebem fenômenos. Os sujeitos que participam em experiências vividas em comum, partilham compreensões, interpretações, comunicações, estabelecendo-se a esfera da intersubjetividade. Para a fenomenologia nada é objetivo, antes de ter sido subjetivo, ou seja, é a subjetividade que permite alcançar graus de objetividade.

Obtidos os discursos dos sujeitos, o pesquisador deve proceder à análise dos mesmos. Entretanto, para tal não existe um método unívoco, pronto, a ser seguido. Existem trajetórias que podem revelar caminhos adequados na busca da compreensão do fenômeno. Trata-se de um caminhar gradativo, relacionado ao próprio desenvolvimento da fenomenologia, enquanto alternativa metodológica de pesquisa nas ciências humanas.

Nesse estudo, tomo como ponto de referência os 
três momentos da trajetória fenomenológica, descritos por MARTINS (1992): a descrição, a redução e a compreensão.

Esse autor, fundamentando-se na visão de Merleau-Ponty, enfoca que a descrição fenomenológica compõe-se por três elementos: a percepção, a consciência que se dirige para o mundo-vida, o sujeito que se vê capaz de experimentar o corpo-vivido através da consciência.

A redução fenomenológica, por sua vez, é o momento em que são selecionadas as partes da descrição que são consideradas essenciais e aquelas que não o são, através da variação imaginativa. O pesquisador imagina cada parte como estando presente ou ausente na experiência, até que a descrição seja reduzida ao essencial para a existência da consciência da experiência.

A compreensão fenomenológica se dá em conjunto com a interpretação. É o momento em que se tenta obter o significado essencial na descrição e na redução. O pesquisador assume o resultado da redução como um conjunto de asserções ou unidades de significado, que se mostram significativas para ele, apontando também para a experiência do sujeito, para a consciência que o sujeito tem do fenômeno. Inicialmente, as unidades de significado são assumidas na linguagem do sujeito que descreve 0 fenômeno (discurso ingênuo), sendo posteriormente transformadas em expressões próprias de discurso que sustentam o que está sendo buscado, por exemplo, um discurso psicológico, educacional, social. Finalmente é organizada uma síntese dessas unidades de significado encontradas, a partir da análise das descrições dos vários sujeitos da pesquisa, sendo buscadas, então, suas convergências, divergências e idiossincrasias.

Acredito que seja importante, após a explanação dessas idéias, voltar-me para alguns aspectos relativos ao desenvolvimento e à compreensão da fenomenologia enquanto método de investigação na enfermagem.

\section{A FENOMENOLOGIA NA ENFERMAGEM}

A fenomenologia originou-se, como já visto, como um movimento na filosofia, tendo sido aplicada, posteriormente, às ciências humanas.

Comenta OMERY (1983) que o ímpeto para o desenvolvimento do método fenomenológico nas ciências humanas foi o próprio insucesso de pesquisadores que utilizavam o método das ciências naturais para explicar o fenômeno de investigação das ciências humanas - o ser humano. Muitos pesquisadores começaram a perceber que aquilo que foi suprimido do experimento científico objetivo - a experiência subjetiva - era mais básico e real na compreensão do conhecimento e dos comportamentos humanos do que as codificações, denominadas pelos pesquisadores experimentais de dados. Assim, muitos pesquisadores, na busca de métodos alternativos de pesquisa, principalmente, na psicologia, começaram a conscientizar-se do valor do método fenomenológico na compreensão da experiência humana.

$\mathrm{Na}$ enfermagem, a utilização da fenomenologia também se deu enquanto busca de alternativas metodológicas de pesquisa. Nesse sentido, ainda de acordo com OMERY (1983), muitos pesquisadores enfermeiros começaram a perceber o uso do método científico como problemático, na medida em que reduz o ser humano, limitando-o em unidades quantitativas pequenas a serem estudadas, não dando pistas de como tais unidades podem ser combinadas num todo dinâmico - o ser humano vivo com o qual o enfermeiro interage na prática.

Discorrendo acerca da importância da fenomenologia na enfermagem, comenta RAY (1985, p.84) que "(..) $\boldsymbol{A}$ filosofia, essencialmente a fenomenologia, oferece um meio pelo qual a enfermeira pode constantemente descobrir sua consciência do inundo. A fenomenologia, então, pode oferecer um meio pelo qual as experiências vividas do mundo-vida das enfermeiras podem ser estudadas e compreendidas".

Acerca da evolução da pesquisa qualitativa em enfermagem nos Estados Unidos, OMERY (1987) afirma que os métodos qualitativos começaram a ser utilizados na década de 60 e, dentre esses métodos, é mencionada a fenomenologia.

No Brasil, os estudos na linha fenomenológica tiveram impulso na enfermagem, a partir, principalmente, do final da década de $80^{\star \star \star}$. ROCHA \& SILVA (1987) comentando acerca das linhas filosóficas e ideológicas na pesquisa em enfermagem no Brasil, identificaram a influência marcante do positivismo nas dissertações e teses desenvolvidas pelos enfermeiros, catalogadas no CEPEn, de 1979 a 1984. As autoras apontaram a tendência de desenvolvimento de alternativas teóricometodológicas, que se fundamentam no materialismo histórico e dialético e na fenomenologia. Tal tendência é compreendida como possibilidade de enriquecimento do conhecimento acerca do objeto de estudo e da prática de enfermagem.

Cabe ressaltar a importância do Seminário Nacional de Pesquisa em Enfermagem (SENPE) que desde $1980 \quad\left(1^{\circ} \quad\right.$ SENPE) vem divulgando a fenomenologia enquanto metodologia de pesquisa para os enfermeiros.

Localizando-se, assim, na década de 80,

*** São trabalhos de enfermagem desenvolvidos através do método fenomenológico: BOEMER (1985), MENDES (1987), BOEMER (1989), FERRAZ (1989), dentre outros 
CAPALBO (1984) acredita que a enfermagem, ao buscar novos horizontes de compreensão, aproxima-se conscientemente ou não, da alternativa metodológica da fenomenologia. Tais horizontes de compreensão envolvem a visão do homem em seu todo e não mais isoladamente e em partes, situado no mundo, em sua totalidade de vida. Envolvem ainda a busca de superar os dualismos clássicos originários da visão naturalista do homem - mente e corpo, indivíduo e sociedade, pessoa e enfermo, saúde e doença, relacionamento pessoal e impessoal.

Enfocando a assistência de enfermagem numa visão fenomenológica, BOEMER et al. (1987) resgatam a percepção do homem como um ser, com um horizonte de possibilidades. Compreendem que para resgatar a totalidade do homem é preciso romper com a visão de homem fragmentado - soma das partes e relações causais entre as manifestações das doenças tratando-se de uma ruptura do discurso comum no cotidiano hospitalar.
Tratando especificamente da enfermagem psiquiátrica, ALENCASTRE (1990) comenta que a fenomenologia pode contribuir para essa área, no que diz respeito a uma melhor compreensão das relações humanas.

Acredito que esse pensar possa ser estendido a outros campos da enfermagem. Compreendo que o assumir algumas idéias básicas da fenomenologia na enfermagem é adotar, essencialmente, uma postura que envolve voltar-se para o outro, enquanto pessoa em sua própria experiência de vida, enquanto sujeito ativo, com múltiplas possibilidades de existir, um vir-a-ser.

Ao despertar para outras dimensões além da biológica, a enfermagem, na busca de conhecimentos, necessita de abordagens diversas de pesquisa. Nesse sentido, a fenomenologia tem se mostrado um caminho possível para a realização de investigações, vislumbrando um novo horizonte de compreensão da enfermagem.

\section{PHENOMENOLOGY: AN ALTERNATIVE TO NURSING RESEARCH}

One of the methodological ways that can be used in research is phenomenology that originated as a movement inside philosophy, being also applied in human sciences. In nursing, the application of phenomenology also represented a search for a methodological alternative in research. The proposal of this work is to contribute with some theoretical subsidies lo the comprehension of phenomenological referential. Initially this work presents some basic ideas of the phenomenology, as a philosophical branch, treating it as a methodological alternative in research, and approaching its utilization by nurses, as a methodology of investigation.

\section{FENOMENOLOGÍA: UNA ALTERNATIVA PARA LA INVESTIGACIÓN EN ENFERMERÍA}

Uno de los pasos metodológicos que puede ser utilizado en las investigaciones es la fenomenología, que se ha originado como un movimiento en la filosofía, siendo después aplicada en las ciencias humanas. En la enfermería la utilización de la fenomenología también ha representado una búsqueda de alternativa metodológica de investigación. La propuesta de este trabajo es contribuir con algunos subsidios teóricos para la comprensión de las referencias fenomenológicas. Al principio, este trabajo presenta algunas ideas fundamentales de la fenomenología, como seguimiento filosófico, para en seguida tratarla como alternativa metodológica de investigación, hasta abordar su utilización por los enfermeros, en cuanto metodología de investigación.

TÉRMINOS CLAVES: enfermería, fenomenología, investigación

\section{REFERÊNCIAS BIBLIOGRÁFICAS}

\section{ALENCASTRE, M.B. Como o pessoal auxiliar de enfermagem psiquiátrica vê $o$ profissional enfermeiro: uma abordagem compreensiva. Ribeirão Preto, 1990. 85 p. Tese (Doutorado) - Escola de Enfermagem de Ribeirão Preto, Universidade de São Paulo. \\ 02. ARANHA, M.L.A.; MARTINS, M.H.P. Filosofando: introdução à filosofia. 2.ed. São Paulo: Moderna, 1993. cap. 131, p. 304-10: O existencialismo.}

03. BICUDO, M.A.V. Sobre a fenomenologia. In:
BICUDO, M.A.V.; ESPOSITO, V.H.C. Pesquisa qualitativa em educação. Piracicaba: Unimep, 1994. p.15-22.

04. BOEMER, M.R. A condução de estudos segundo a metodologia de investigação fenomenológica. Rev.latinoam.enfermagem, v. 2, n. 1, p. 83-94, jan. 1994.

05. BOEMER, M.R. et al. A quem oferecemos o cuidado de enfermagem: uma visão fenomenológica. In: SEMINÁRIO NACIONAL - O PERFIL E A COMPETÊNCIA DO ENFERMEIRO, 1, Brasília, 1987. Anais. p.95-103 
06. CAPALBO, C. Alternativas metodológicas de pesquisa. In: SEMINÁRIO NACIONAL DE PESQUISA EM ENFERMAGEM, 3, Florianópolis, 1984. Anais. Florianópolis, Ed. UFSC, 1984. p. 130-57.

07. CAPALBO, C. Fenomenologia e ciências humanas. Rio de Janeiro, J. Ozon, s.d.

08. COHEN, M.Z. A historical overview of the phenomenologic movement. Image: Journal of Nursing Scholarship, v. 19, n. 1, p. 31-4, Spring 1987.

09. DARTIGUES, A. O que é a fenomenologia? Trad. de Maria José J.G. de Almeida: Rio de Janeiro, Eldorado Tijuca, 1973.

10. FORGHIERI, Y.C. Fenomenologia do existir de urna professora universitária. São Paulo, 1991. 195 p. Tese (Livre-Docência) - Instituto de Psicologia, Universidade de São Paulo.

11. FRANCA, L. Noções de história da filosofia. 22.ed. Rio de Janeiro: Agired, 1978. cap. 3, p. 249-52: A fenornenologia.

12. GILES, T.R. História do existencialismo e da fenomenologia. São Paulo: EPU/EDUSP, 1975, p. 129-84. v. 1.

13. HUSSERL, E. A filosofia como ciência do rigor. 2. ed. Coimbra: Atlantida, 1965.

14. MARTINS, J.; BICUDO, M.A.V. A pesquisa qualitativa em psicologia: fundamentos e recursos básicos. São Paulo: Moraes, 1989.

15. MARTINS, J. et al. A fenomenologia como alternativa metodológica para pesquisa: algumas considerações. Rev.Esc.Enf.USP, v. 24, n. 1, p. 13947, abr. 1990.

16. MARTINS, J. Um enfoque fenomenológico do currículo: educação como poíesis. São Paulo: Cortez, 1992.

17. MOURA, C.A.R. Crítica da razão na fenomenologia. São Paulo: EDUSP, 1989. cap. 5, p. 157-90: O território da filosofia.

18. OMERY, A. Phenomenology: a method for nursing research. Adv.Nurs.Sci., v. 5,11. 2, p. 49-62, jan. 1983.

19. . Qualitative research designs in the critical care setting: review and application. Heart Lung, v. 16, n. 4, p. 432-36,jul. 1987.

20. RAY, M.A. A philosophical method to study nursing phenomena. In: LEININGER, M.M. Qualitative research methods in nursing. Orlando: Grune \& Stratton, 1985. cap. 5, p. 8 1-92.

21. ROCHA, S.M.M.; SILVA, G.B. Linhas filosóficas e ideológicas na pesquisa em enfermagem no Brasil. Rev.Bras.Enf., v. 40, 11. 4, p. 2 14-20, out./dez. 1987.

\section{REFERÊNCIAS CONSULTADAS}

01. BOEMER, M.R. A morte, o morrer e o morrendo: estudo de pacientes terminais. Ribeirão Preto, 1985. 205p. Tese (Doutorado) - Escola de Enfermagem de Ribeirão Preto, Universidade de São Paulo.

02. O fenômeno morte: o pensar, o conviver e o educar. Ribeirão Preto, 1989. 111p. Tese (Livre-Docência) - Escola de Enfermagem de Ribeirão Preto, Universidade de São Paulo.

03. FERRAZ, C.A. Compreensão do exercício profissional do enfermeiro: uma análise fenomenológica. Ribeirão Preto, 1989. 83p. Dissertação (Mestrado) - Escola de Enfermagem de Ribeirão Preto, Universidade de São Paulo.

04. MENDES, I.S.S. O ser hanseniano. Ribeirão Preto, 1987. 98p. Tese (Doutorado) - Escola de Enfermagem de Ribeirão Preto, Universidade de São Paulo. 